Van der Sluys Veer, J., Choufoer, J.C., Querido, A., VAN Der Heul, R.O., Hollander, C.F. \& VAN RiJssel, T.G. (1964) Metastasizing islet cell tumour of the pancreas associated with hypoglycaemia and carcinoid syndrome.
Lancet, i, 1416.

Zollinger, R.M. \& Elliott, D.W. (1959) Pancreatic endocrine function and peptic ulceration. Gastroenterology, 37, 401 .

\title{
Macroglossia, abnormal umbilicus and hypoglycaemia (Beckwith's syndrome)
}

\author{
M. W. MONCRIEFF* \\ M.A., B.M., M.R.C.P. \\ Lecturer in Paediatrics, \\ University of Birmingham
}

\author{
A. R. Goldsmith \\ M.B.B.S. \\ Registrar in Pathology, \\ Birmingham Children's Hospital
}

\author{
J. R. MANN \\ M.B., M.R.C.P., D.C.H. \\ Registrar in Paediatrics, \\ Birmingham Children's Hospital \\ G. W. Chance \\ M.B., M.R.C.P., D.C.H. \\ Senior Lecturer in Paediatrics, \\ University of Birmingham
}

\section{Introduction}

The syndrome of exomphalos, macroglossia, postnatal somatic gigantism and severe hypoglycaemia in various combinations was first described in seven infants by Beckwith (1963) and Beckwith et al. (1964). At necropsy the main features were cytomegaly of the foetal adrenal cortex, renal medullary dysplasia, and hyperplasia of the pancreas and kidneys. Wiedemann (1964) reported three siblings of a consanguineous marriage who had macroglossia and exomphalos. The survivor developed post-natal somatic gigantism and accelerated bone growth. Irving (1967) reported eleven children with exomphalos and macroglossia, nine of whom had a birth weight on or above the 90th centile for their gestational age. Ten of the children had a facial naevus, seven had a linear indentation of the ear lobe and three had a dome-like elevation of the posterior part of the diaphragm. The six surviving children developed a characteristic facies with prognathos, mid-facial under development and slight exophthalmos, and a mid-line frontal ridge. Postnatal somatic gigantism occurred in five of the six survivors. A further seven cases with macroglossia and umbilical abnormality were reported by Shafer (1968). Severe hypoglycaemia and birth weight above the mean for their gestational age were the main features of the three cases reported by Combs, Grunt \& Brandt (1966). The principal features of the previously reported cases are shown in Table 1.

Two further cases are reported who developed hypocalcaemia, in addition to the main features already described. One survived and now has hemihypertrophy.

TABLE 1. The main features of Beckwith's syndrome (not all are present in every case)

\begin{tabular}{lll}
\hline \multicolumn{1}{c}{ Birth } & \multicolumn{1}{c}{ Childhood } & \multicolumn{1}{c}{ Necropsy } \\
\hline Macroglossia* & Post-natal gigantism* & Cytomegaly of foetal \\
Abnormal umbilicus* & Characteristic facies* & adrenal cortex* \\
Somatic gigantism* & Microcephaly* & Renal medullary \\
Facial naevus* & Mental retardation* & dysplasia* \\
Hypoglycaemia* & Hemihypertrophy & Hyperplasia of: \\
Enlarged kidneys* & Malignant disease & Pancreas* \\
Enlarged liver* & & Kidneys* \\
Ear lobe anomaly & & \\
Abnormality of the diaphragm & & \\
Hypocalcaemia & & \\
Polycythaemia & & \\
\hline
\end{tabular}

* Commonly found.

* Now Consultant Paediatrician, Derby Children's Hospital. 


\section{Case reports}

Case 1

This boy was born at 35 weeks gestation by a normal delivery at home after an uneventful pregnancy, during which his mother had taken iron and folic acid. His two siblings are normal. Two cyanotic attacks shortly after birth led to his admission to hospital at $15 \mathrm{hr}$ of age. Physical and neurological assessment were consistent with his gestational age, but he weighed $2.72 \mathrm{~kg}$ (75th centile). His length was $47 \mathrm{~cm}$ and his head circumference $33 \mathrm{~cm}$. He had a large protruding tongue, and a small umbilical hernia. Both kidneys were enlarged.

At $18 \mathrm{hr}$ of age he became hyperactive and jittery, the capillary blood sugar was $28 \mathrm{mg} / 100 \mathrm{ml}$, and he was treated with an intravenous infusion of dextrose and fructose. However, he remained irritable and as the serum calcium was found to be $6.4 \mathrm{mg} / 100 \mathrm{ml}$ he was given calcium gluconate intravenously with considerable improvement in his symptoms. By $48 \mathrm{hr}$ of age his blood sugar had risen to $56 \mathrm{mg} / 100 \mathrm{ml}$ and his serum calcium to $9.5 \mathrm{mg} / 100 \mathrm{ml}$ and both thereafter remained normal.

Macroglossia made feeding difficult and on several occasions caused temporary obstruction of the airways, but by 1 month of age he was entirely bottle fed. At 4 months of age hemihypertrophy was first noticed. A radiograph of the limbs confirmed that the bones of the right side were larger than those of the left. At 13 months of age his height was on the 25th centile and his psychomotor development approximated to that of a child of 10 months.

An intravenous pyelogram performed at the age of 6 weeks showed a moderately large left kidney with normal architecture and good concentration and excretion. The right kidney was markedly hydronephrotic due to pelvi-ureteric obstruction. A second pyelogram at the age of 13 months showed similar, but less marked, changes in the left kidney. The urine has remained uninfected and surgical relief of the pelvi-ureteric obstructions is planned.

Chromosomes from a lymphocyte culture, which were examined in the cytogenetics unit of The Children's Hospital, Birmingham, were normal.

\section{Case 2}

This boy, the first of dizygotic twins, was born by a normal vertex delivery at 37 weeks gestation. Pregnancy had been complicated by hydramnios and anaemia. Regular respiration was established by $2 \frac{1}{2} \mathrm{~min}$. On examination he had a large tongue, an exomphalos measuring $5 \mathrm{~cm}$ across the base (Fig. 1), and enlarged kidneys. The skin was red, shiny and thin. His weight on the 3rd day of life was $4.0 \mathrm{~kg}$ (90th centile), his head circumference was $35 \mathrm{~cm}$ and his length $47 \mathrm{~cm}$.
He was transferred to The Children's Hospital, Birmingham, and in view of the size of the exomphalos and the anticipated metabolic abnormalities, operative correction was not undertaken, and it was treated with applications of mercurochrome, $2.5 \%$, twice a day. The results of biochemical investigations

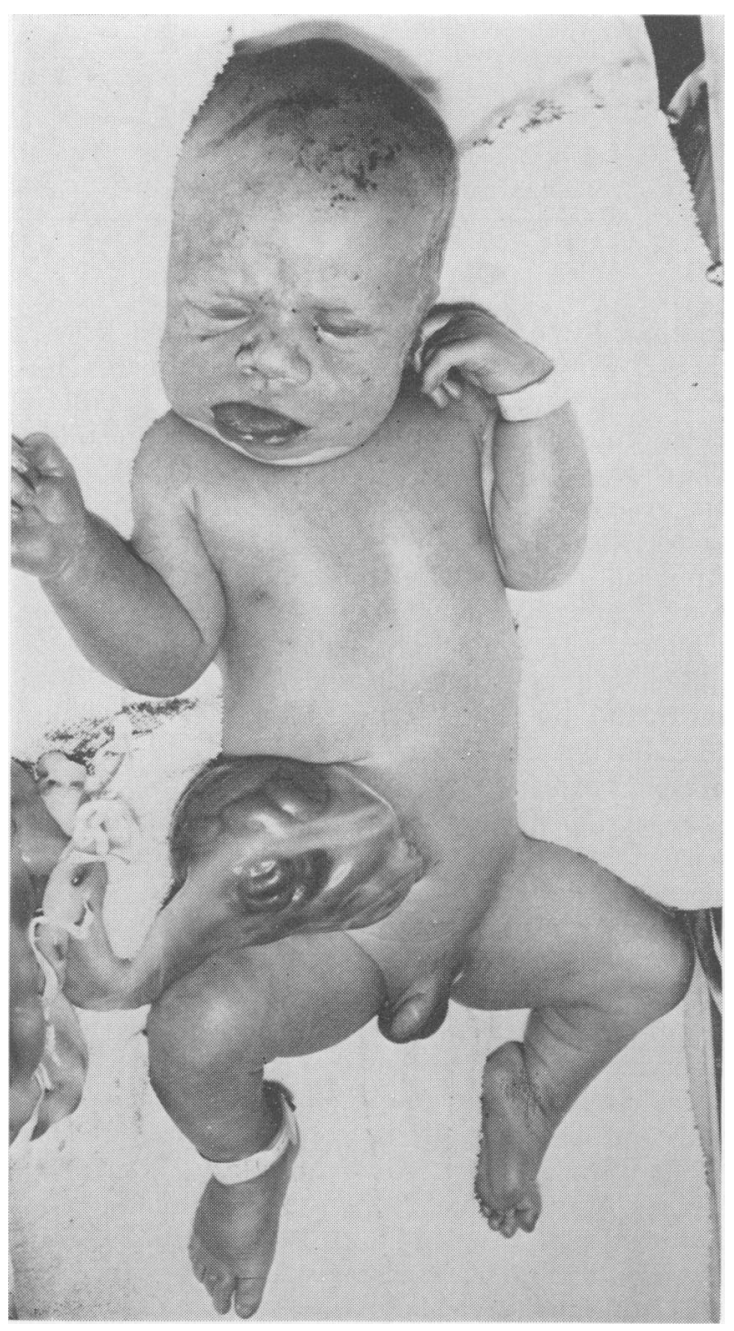

FIG. 1. Case 2 showing macroglossia and exomphalos.

are shown in Table 2. Hypoglycaemia was detected at $12 \mathrm{hr}$ of age and he was treated with dextrose and fructose intravenously. On the 2 nd day of life he developed metabolic acidosis and hypocalcaemia and he was treated with intravenous sodium bicarbonate and calcium gluconate with considerable improvement. Respiratory distress developed on the 3rd day and persisted for 3 days. When oral feeding was started and intravenous therapy dis- 
TABLE 2. Results of investigations (Case 2)

\begin{tabular}{|c|c|c|c|c|c|c|c|c|c|}
\hline & \multicolumn{9}{|c|}{ Day of life } \\
\hline & 1 & $\begin{array}{c}2 \\
\text { (a.m.) }\end{array}$ & $\begin{array}{c}2 \\
\text { (p.m.) }\end{array}$ & 3 & 4 & 6 & 8 & 9 & 10 \\
\hline $\begin{array}{l}\text { Blood sugar } \\
(\mathrm{mg} / 100 \mathrm{ml})\end{array}$ & 28 & 86 & 70 & 94 & 60 & 41 & 34 & 63 & 58 \\
\hline $\begin{array}{l}\text { Serum calcium } \\
(\mathrm{mg} / 100 \mathrm{ml})\end{array}$ & & $4 \cdot 7$ & $8 \cdot 2$ & $7 \cdot 5$ & $7 \cdot 2$ & $6 \cdot 5$ & & $6 \cdot 2$ & $7 \cdot 5$ \\
\hline pH & & $7 \cdot 18$ & $7 \cdot 29$ & $7 \cdot 08$ & $7 \cdot 27$ & & & $7 \cdot 29$ & \\
\hline $\mathrm{PCO}_{2}$ & & 37 & $28 \cdot 5$ & 61 & 50 & & & 39 & \\
\hline Bicarbonate & & 14 & $16 \cdot 5$ & $14 \cdot 5$ & $20 \cdot 5$ & & & $18 \cdot 5$ & \\
\hline Base excess & & $-16 \cdot 5$ & $-11 \cdot 5$ & -13 & $-4 \cdot 5$ & & & $-7 \cdot 5$ & \\
\hline
\end{tabular}

continued, the blood sugar again fell, and he was treated with additional glucose orally and prednisone $1 \mathrm{mg}$ twice a day. His general condition deteriorated with oedema of his hands and feet, and diarrhoea and vomiting, and intravenous therapy was restarted. However, he continued to deteriorate and he died on the 16th day of life. Chromosomes from an antemortem lymphocyte culture, which were examined in the cytogenetics unit of The Children's Hospital, Birmingham, were normal.

The second twin, a female, weighed $2.5 \mathrm{~kg}$ at birth and on examination had no abnormalities. She did not develop hypoglycaemia and has progressed normally.

A steroid augmented oral glucose tolerance test was performed on the mother and gave a normal result.

Necropsy. The skin and internal organs were stained uniformly pink. The tongue was large and protruded from the mouth and there was a large central exomphalos measuring $11 \mathrm{~cm}$ in diameter, which contained small intestine, colon, and part of the liver. Many of the loops of small intestine were adherent and partially necrotic. The liver weighed $228 \mathrm{~g}$ (normal $185 \mathrm{~g}$ ), the right kidney $37 \mathrm{~g}$, the left kidney $41 \mathrm{~g}$ (normal $29 \mathrm{~g}$ ) and the adrenal glands together $9 \mathrm{~g}$ (normal $10.5 \mathrm{~g}$ ). (Normal weights from Potter, 1952.) The pancreas was not weighed, but was not obviously enlarged.

Microscopy. The main abnormalities were confined to the lungs, which showed pneumonia, the kidneys and the adrenal glands. The kidneys showed marked reduction of the number of tubules in the medulla (Fig. 2). This appeared to be due to absence of the loops of Henle leaving only the collecting tubules. These were separated by abundant, highly cellular, connective tissue containing aggregates of erythroid and myeloid cells as well as fibroblasts. The stroma did not form concentric sheaths around the collecting tubules as commonly seen in renal dysplasia. Several tubules contained calcific material.

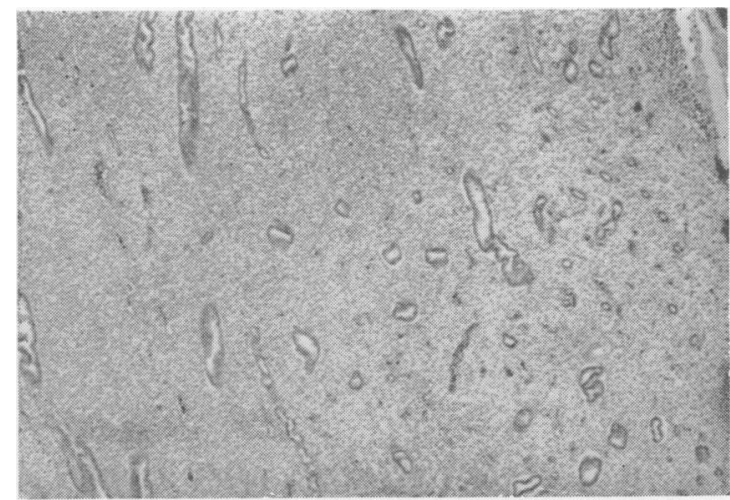

FIG. 2. Section of kidney from Case 2 showing renal medullary dysplasia. H \& $\mathrm{E}, \times \mathbf{7 4 0}$.

The cotices were unremarkable and there were no inflammatory changes. In the adrenal glands the foetal cortex showed moderate bilateral cytomegaly (Fig. 3) but the definitive cortex was normal.

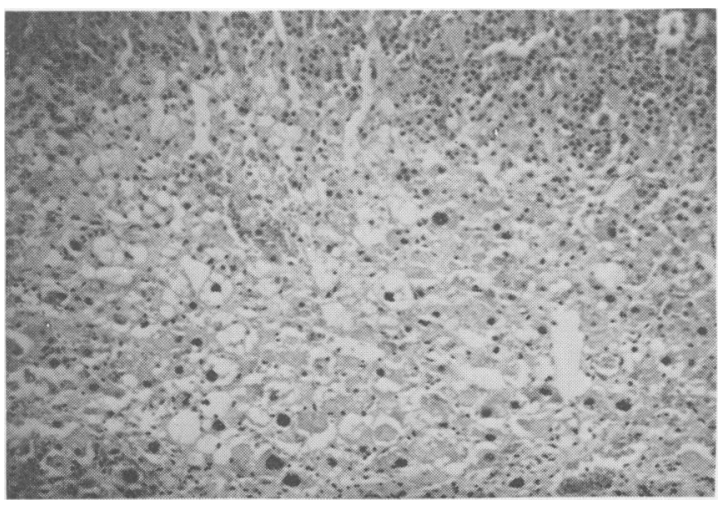

Fig. 3. Section of adrenal cortex from Case 2 showing numerous, abnormally large cells with large, darkstaining nuclei. $\mathrm{H} \& \mathrm{E}, \times 100$. 
The pancreas and tongue were histologically normal. The liver showed passive venous congestion.

\section{Comment}

The two infants described here showed many of the features reported in Beckwith's syndrome. They had macroglossia, an umbilical abnormality, hypoglycaemia (as defined by Cornblath \& Schwartz, 1966) and birth weight above the mean for the gestational age. Hypoglycaemia occurred on the 2nd and 3rd days of life in the cases reported by Combs et al. (1966), and was persistent and severe, but in our cases hypoglycaemia occurred on the 1 st day of life and recurred only in Case 2. In addition, both the infants developed hypocalcaemia which has been reported in only two cases previously (Combs et al., 1966; Harris, 1969). The cause of the hypocalcaemia is unknown, but it has been reported in association with hypoglycaemia by Cornblath et al. (1964).

Although a prominent satellited short arm of one of the G (21/22) group of chromosomes was found in three of the cases reported by Irving (1967), the chromosomes in our patients were normal. In view of the familial cases reported by Irving (1967) and Wiedemann (1964) this syndrome may be inherited as an autosomal recessive.

The necropsy findings in Case 2 were similar to those previously reported. There was enlargement of the kidneys, renal medullary dysplasia and cytomegaly of the foetal adrenal cortex. These abnormalities were also found in all the cases examined by Irving (1967) and Beckwith (personal communication 1969).

Renal medullary dysplasia is most commonly seen in obstructive hydronephrosis, the so-called delta lesion (Bernstein \& Meyer, 1967), but the medulla is usually flattened and there are glomerular cysts in the subcapsular zone, features which were not present in our case. The only other types of renal dysplasia, in which malformation is virtually limited to the medulla, are medullary cystic disease and medullary sponge kidney (Heptinstall, 1966), but cystic changes were not found in our case. The appearances in the kidney have no resemblance to the common types of renal dysplasia which involve the cortex as well as the medulla. 'Cytomegaly of the adrenal cortex' refers to a condition in which the cells in the foetal cortex are abnormally large, with finely granular, eosinophilic cytoplasm. The nuclei are large and hyperchromatic and may show vacuoles. This condition is not confined to Beckwith's syndrome, as Craig \& Landing (1951) found it in $3 \%$ of neonatal deaths, and in $6.5 \%$ of stillbirths. The commonest associated disease in their experience was erythroblastosis foetalis. Cytomegaly of the adrenal cortex has also been reported in association with adrenal carcinoma (Sherman, Bass \& Fetterman, 1958), congenital adrenal hypoplasia (Kerenyi, 1961), and with various other congenital abnormalities (Beatty \& Hawes, 1955). The pink staining of the skin and internal organs was due to mercurochrome, some of which must have been absorbed through the exomphalos. The deposits of calcium in the renal tubules were considered to be due to mercury intoxication which is known to cause nephrocalcinosis (Allen, 1962).

Hemihypertrophy, which Fraumeni \& Miller (1967) and Fraumeni, Geiser \& Manning (1967) found to be associated with malignant disease in the kidneys, adrenal glands and liver, has developed in our surviving case. Beckwith (personal communication 1969) reported that one of his cases had also developed hemihypertrophy. A child with exomphalos, macroglossia and crossed hemihypertrophy, who developed a Wilms' tumour, was described by Wilson \& Orlin (1965). We also know of a child with macroglossia and exomphalos who developed a hepatoblastoma (Oldham, personal communication 1969). It seems, therefore, that children with this syndrome who survive the newborn period have a high risk of developing malignant disease.

Although this is a rare syndrome its recognition is important as the metabolic abnormalities in the newborn period can be anticipated. The prognosis for the children who survive the newborn period must be guarded in view of the risk of subsequent malignant disease.

\section{Acknowledgments}

We would like to thank $\operatorname{Dr}$ R. H. R. White for allowing us to publish details of case two, Dr J. B. Beckwith for letting us see the manuscript of his paper, and Dr A. H Cameron for his helpful advice.

\section{References}

Allen, A.C. (1962) The kidney. Medical and Surgical Diseases, 2nd edn, p. 351. Churchill, London.

BeatTy, E.C. \& Hawes, C.R. (1955) Cytomegaly of the adrenal gland. American Journal of Diseases of Children, $89,463$.

BeCKWITH, J.B. (1963) Extreme cytomegaly of the adrenal fetal cortex, omphalocele, hyperplasia of kidneys and pancreas, and Leydig-cell hyperplasia: another syndrome? Presented at Annual Meeting of Western Society for Pediatric Research.

BeCKwith, J.B., Wang, C., Donnell, G.N. \& Gwinn, J.L. (1964) Hyperplastic fetal visceromegaly, with macroglossia, omphalocele, cytomegaly of the adrenal fetal cortex, post-natal somatic gigantism, and other abnormalities: A newly recognized syndrome. Abstract read by title, at Annual Meeting of American Pediatric Society.

Bernstein, J. \& Meyer, R. (1967) Parenchymal maldevelopment of the kidney. Practice of Pediatrics, Vol. III, Chap. 26, p. 12. Harper \& Row, Maryland.

Combs, J.T., Grunt, J.A. \& BrandT, I.K. (1966). New syndrome of neonatal hypoglycaemia. Association with visceromegaly, macroglossia, microcephaly and abnormal umbilicus. New England Journal of Medicine, 275, 236. 
Cornblath, M., Wybregt, S.K., Baens, G.S. \& Klein, R.I. (1964) Symptomatic neonatal hypoglycaemia: studies of carbohydrate metabolism in the newborn infant. VIII. Pediatrics, 33, 388.

Cornblath, M. \& Schwartz, R. (1966) Disorders of Carbohydrate Metabolism in Infancy, p. 82. Saunders, Philadelphia.

Craig, J.M. \& Landing, B.H. (1951) Anaplastic cells of fetal adrenal cortex. American Journal of Clinical Pathology, 21, 940.

Fraumeni, J.F. \& Miller, R.W. (1967) Adrenocortical neoplasms with hemihypertrophy, brain tumors and other disorders. Journal of Pediatrics, 70, 129.

Fraumeni, J.R., Geiser, C.F. \& ManNing, M.D. (1967) Wilms' tumor and congenital hemihypertrophy: report of five new cases and review of literature. Pediatrics, 40, 886.

HARRIS, F. (1969) Exomphalos-Macroglossia Syndrome (Beckwith). Proceedings of the Royal Society of Medicine. (In press.)

HePtinstall, R.H. (1966) Pathology of the Kidney, p. 93. Churchill, London.
IRVING, I.M. (1967) Exomphalos with macroglossia: a study of eleven cases. Journal of Pediatric Surgery, 2, 499.

KerenYI, N. (1961) Congenital adrenal hypoplasia. Report of a case with extreme adrenal hypoplasia and neurohypophyseal aplasia. Archives of Pathology, 71, 336.

Potter, E.L. (1952) Pathology of the Fetus and Newliorn, 1st edn, p. 13. Year Book Publishers, Chicago.

Shafer, A.D. (1968) Primary macroglossia. Clinical Pediatrics, 7, 357.

Sherman, F.E., Bass, L.W. \& Fetterman, G.H. (1958) Congenital rnetastasizing adrenal cortical carcinoma associated with cytomegaly of the fetal adrenal cortex. American Journal of Clinical Pathology, 30, 439.

WiLson, F.C. \& ORLIN, H. (1965) Crossed congenital hemihypertrophy associated with Wilms' tumor. Journal of Bone and Joint Surgery, 47A, 1609.

WiedemanN, H.R. (1964) Complexe malformatif familial avec hernie ombilical et macroglossei, un 'syndrome nouveau'. Journal de Génétique humaine, 13, 223.

\title{
Peripheral sensorimotor neuropathy in association with a seminoma of an undescended testicle
}

\author{
W. A. LitTler \\ M.B., Ch.B., M.R.C.P. \\ Senior House Officer in Medicine, \\ Royal Southern Hospital, Liverpool
}

\section{Introduction}

Denny-Brown (1948) described two cases of sensory neuropathy associated with occult carcinoma of the bronchus. Since then various neurological syndromes, which seem unrelated to neural metastases, have been described; these include cortical cerebellar degenerations, sensory neuropathy, mixed forms, sensorimotor forms and neuromuscular disorders. Brain \& Henson (1958) first used the term 'carcinomatous neuromyopathy' to describe this group. Croft \& Wilkinson (1965) examined 1521 patients admitted to hospital because of some form of carcinomatosis and found evidence of neuromyopathy in over $10 \%$ (162 cases) of the whole series. Bronchial carcinoma is the one most commonly associated with neuromyopathy but other malignant tumours have been incriminated, including ovarian, gastro-intestinal, mammary, oesophageal, prostatic and uterine carcinomas, multiple myeloma and disseminated lymphoma. In a recent review of this subject Croft \& Wilkinson (1969) listed one case of a seminoma associated with a peripheral sensorimotor neuropathy. The following case report is an example of a sensorimotor neuropathy associated with a seminoma of an undescended testicle.

\section{Case report}

The patient, a 53-year-old bachelor was admitted to hospital with a 3 week history of progressive numbness and weakness in both his hands and feet. He smoked thirty-five cigarettes a day and drank up to 6 pints of beer every night, but ate regular, adequate meals cooked for him by his sister. He worked as a dock labourer. He had not been treated with any neurotoxic drugs and there was no family history of neurological disease. Twenty years earlier a left sided inguinal hernia had been repaired; the hernia had been associated with an undescended testicle and the patient had been told that the left testicle was within the abdomen and had not been removed (no clinical notes available).

Examination showed a thin, ill-looking man. The cardiovascular and respiratory systems were clinically normal. Palpation of the abdomen revealed a fixed, non-tender, cystic mass, the size of a grapefruit, in the left iliac fossa. The spleen was thought to be enlarged 3 in below the left costal margin. The left testicle was absent from the scrotum, the right testicle appeared normal. Rectal examination was normal. In the central nervous system there were signs of a sensorimotor neuropathy with loss of sensation to all modalities in the glove-and-stocking 